\title{
Helicobacter Pylori Variants with ABC-Type Tyrosine Phosphorylation Motif in Gastric Biopsies of Ghanaian Patients
}

\author{
Emmanuel A. Tagoe $\mathbb{D}^{1},{ }^{1,2}$ Gordon A. Awandare $\left(\mathbb{D},{ }^{1}\right.$ Osbourne Quaye ${ }^{(D)}{ }^{1}$ \\ Richard H. Asmah $\mathbb{D}^{2,3}$ Timothy N. Archampong $\left(\mathbb{D},{ }^{4}\right.$ Mahasin A. Osman, ${ }^{5}$ \\ and Charles A. Brown ${(\mathbb{D})^{2}}^{2}$ \\ ${ }^{1}$ West African Centre for Cell Biology of Infectious Pathogens (WACCBIP)/Department of Biochemistry, Cell and Molecular Biology, \\ University of Ghana, Legon, Accra, Ghana \\ ${ }^{2}$ Department of Medical Laboratory Sciences, University of Ghana, Korle Bu, Accra, Ghana \\ ${ }^{3}$ Department of Biomedical Sciences, School of Basic and Biomedical Sciences, University of Allied Health Sciences, Ho, Ghana \\ ${ }^{4}$ Department of Medicine, University of Ghana Medical School, University of Ghana, Korle Bu, Accra, Ghana \\ ${ }^{5}$ Departments of Medicine, College of Medicine and Life Sciences, University of Toledo, OH 34614, USA
}

Correspondence should be addressed to Emmanuel A. Tagoe; eatagoe@ug.edu.gh and Charles A. Brown; cabrown@chs.edu.gh

Received 13 November 2020; Revised 17 March 2021; Accepted 22 March 2021; Published 31 March 2021

Academic Editor: Maria Bayliak

Copyright (c) 2021 Emmanuel A. Tagoe et al. This is an open access article distributed under the Creative Commons Attribution License, which permits unrestricted use, distribution, and reproduction in any medium, provided the original work is properly cited.

\begin{abstract}
Background. Helicobacter pylori pathogenicity and disease severity are determined by the tyrosine phosphorylation motifs of CagA protein. This study is aimed at detecting the presence of $H$. pylori and identifying the CagA tyrosine phosphorylation motifs in Ghanaian patients. Material and Methods. A total of 94 archival genomic DNA samples from gastric biopsies were used for the study, and $H$. pylori was detected by amplifying the $16 \mathrm{~S}$ rRNA gene. The 3 '-end variable region of the cagA gene was amplified, and the entire $3^{\prime}$-end was sequenced and translated into amino acids. Results. H. pylori was detected in 53.2\% (50/94) of the samples, and all the detected bacteria harboured the cagA gene. Two variants of the bacteria were identified based on the size of the amplified cagA gene: $207 \mathrm{bp}$ and $285 \mathrm{bp}$. The $207 \mathrm{bp}$ and $285 \mathrm{bp}$ variants accounted for $74 \%$ and $22 \%$, respectively, and $4 \%$ showed both fragments. Translated amino acid sequence of the cagA gene showed EPIYA-A, EPIYA-B, and EPIYA-C (ABC type) motifs, indicating the Western variant. The CagA protein C-terminal showed insertion of amino acids in the sequence flanking the EPIYA-A motif at the N-terminal and a complete deletion of the EPIYA-CC and EPIYA-CCC motifs together with the flanking sequences. Conclusions. H. pylori identified were Western variant (ABC type) with unique amino acid insertions, suggesting unique variants in Ghanaian patients. Further investigation is however required to understand the role of the molecular diversity of the variant in gastric disease outcome.
\end{abstract}

\section{Introduction}

Helicobacter pylori (H. pylori) is a major etiological agent of human gastric disease, and almost half of the world's population is infected with the pathogen [1]. Infection occurs in early childhood, and the bacteria transmission has been associated with socioeconomic factors [2]. H. pylori variants are diverse across populations [3], and the diversity has been attributed to polymorphism of virulent genes encoded by a $40 \mathrm{~kb}$ cag-pathogenic island (cag-PAI) [4]. The cytotoxinassociated $\mathrm{A}$ (cagA) and vacuolating cytotoxin (vacA) genes are among the well-studied $H$. pylori genes of the cag-PAI that account for the pathogenicity of the bacteria [5]. Though, almost $70 \%$ of $H$. pylori variants globally contain the cagA gene, the distribution of the cagA-positive variant varies geographically [6]. A prevalence of $90-95 \%$ cagA-positive variants has been reported in East Asia as against $60 \%$ in Western countries [6]. The cagA gene encodes a $120-145 \mathrm{kDa}$ oncogenic CagA protein which is translocated into the host cell via a type IV secretion system [7]. The oncogenic effect of the protein in the cell largely depends on a highly polymorphic C-terminal region $[8,9]$. Within the CagA C- 
terminal variable region are repeated Glu-Pro-Ile-Tyr-Ala (EPIYA) motifs. The motifs were assigned EPIYA-A, EPIYA-B, EPIYA-C, and EPIYA-D, and the assignments depend on the amino acid sequences that flank the motifs [6]. The EPIYA motifs, together with the flanking amino acid sequences, delineate $H$. pylori as either Western or East Asian variant [10]. The Western strain contains conserved EPIYA$A$ and EPIYA-B motifs in addition to a single or repeated EPIYA-C, while the East Asia strain contains EPIYA-D and the conserved EPIYA-A and EPIYA-B motifs [11].

The Western strain, which habours a greater number of repeated EPIYA-C motifs, has been shown to be more pathogenic than variants with less number of the motifs, but not as pathogenic as the East Asian strain with the EPIYA-D motifs [12]. The EPIYAs are the sites for CagA phosphorylation in host cells, and the phosphorylated or nonphosphorylated protein has been implicated in epithelial cells' morphological changes and gastric disorders [11]. Evidence suggests that phosphorylation of the EPIYA sites is preferential; EPIYA-A and EPIYA-C phosphorylation occurs in the Western strain, and EPIYA-B and EPIYA-D occurs in the East Asian strain [13].

As a mechanism underlying CagA-associated pathogenesis, translocated and phosphorylated CagA tethers at the plasma membrane and recruits $\mathrm{SH} 2$ domain-containing protein tyrosine phosphatase-2 (SHP2) from the cytoplasm to the plasma membrane [14]. The number of EPIYA motifs potentiates the recruitment of SHP2 and enhances CagASHP2 interaction, leading to cell-cell contact disruption, cytoskeletal rearrangement, and cell elongation [15]. The EPIYA-D-containing CagA more strongly interacts with SHP2 than the protein with the EPIYA-C motif, and the interaction increases SHP2 phosphatase activity in the East Asia strain compared to the Western strain [16]. Interaction of CagA with SHP2 via the EPIYA motifs has been shown to predispose individuals infected with $H$. pylori to precancerous lesion and gastric cancer [17]. Strain diversity of the bacteria, based on the CagA variants, has therefore been implicated as an important tool in predicting risk of developing gastric dysplasia and also serving as a prognostic marker [18].

In a recent study among Ghanaian patients diagnosed with gastric dysplasia, cagA gene was more likely to be detected in patients with duodenal ulcer [19]. However, no study has characterized $H$. pylori cagA gene based on the amino acid sequences of the C-terminal to determine bacteria diversity in Ghana. The current study is aimed at investigating the diversity of cagA-positive $H$. pylori variant in Ghana by amplifying the 3 ' -end variable region using multiplex PCR and performing amino acid sequence alignment to determine the predominant EPIYA motifs of the variant in the population.

\section{Material and Methods}

Archival frozen genomic DNA samples obtained from patients diagnosed with gastric disease at Korle Bu Teaching Hospital in the southern part of Ghana were used in the current study. A total of 94 genomic DNA samples were retrieved, and PCR was used to detect the presence of the bacteria by amplifying the $16 S r R N A$ gene. The samples found to contain $H$. pylori DNA were selected for further PCR analysis to identify $H$. pylori cagA gene $3^{\prime}$-end variable region. DNA extracted from cagA-positive $H$. pylori (ATCC 435403) strain, using a bacterial genomic DNA purification kit (Wizard Genomic DNA Purification Kit, Promega, USA), was used as control. The control DNA concentration and purity were determined using NanoDrop 2000/2000c (Thermo Fisher Scientific, USA) spectrophotometer and stored at $-20^{\circ} \mathrm{C}$ until ready to use.

2.1. Amplification of H. pylori $16 S$ rRNA and cagA Gene $3^{\prime}$ -End Variable Region. Detection of H. pylori 16S rRNA gene in the genomic DNA samples was by PCR using a set of primers (Table 1) and ready-to-use OneTaq Quick-Load 2X Master Mix (BioLabs Inc., England) by following the manufacture's reaction conditions. Each $25 \mu \mathrm{L}$ PCR reaction mixture had the following components and final concentrations: $1 \mathrm{x}$ reaction buffer, $0.5 \mu \mathrm{M}$ each of the forward and reverse primers, and $0.1 \mu \mathrm{g} / \mu \mathrm{L}$ genomic DNA. Nucleasefree water was added to obtain the reaction volume. The reaction mixture was subjected to an initial denaturation at $94^{\circ} \mathrm{C}$ for 30 seconds, 30 cycles of denaturation at $94^{\circ} \mathrm{C}$ for $30 \mathrm{sec}$ onds, annealing at $68^{\circ} \mathrm{C}$ for 1 minute, and extension at $68^{\circ} \mathrm{C}$ for 1 minute. Final extension was performed at $68^{\circ} \mathrm{C}$ for 5 minutes.

The cagA gene $3^{\prime}$-end variable region was amplified from genomic DNA samples found to contain $H$. pylori DNA using multiplex PCR. Each $50 \mu \mathrm{L}$ PCR reaction mixture had the following components and final concentrations: $1 x$ Go Green Go Taq pol reaction buffer, 1.25 units Go Taq G2 DNA pol, $0.25 \mu \mathrm{M}$ of each dNTP, $0.5 \mu \mathrm{M}$ of each primer, and $0.2 \mu \mathrm{g} / \mu \mathrm{L}$ genomic DNA sample. Nuclease-free water was added to make up the reaction volume. The PCR machine was programmed at the following cycling conditions for the amplification of the targeted gene: initial denaturation at $94^{\circ} \mathrm{C}$ for 1 minute, 35 cycles of denaturation at $94^{\circ} \mathrm{C}$ for 55 seconds, $53.1^{\circ} \mathrm{C}$ annealing for 1 minute, and $72^{\circ} \mathrm{C}$ extension for 1 minute and 30 seconds. Final extension was at $72^{\circ} \mathrm{C}$ for 5 minutes. The sets of primers used for cag $A$ gene characterization and expected amplification product sizes are shown in Table 1.

In both PCR setups, the extracted control DNA sample and PCR reaction mixture without DNA material were used as positive and negative controls, respectively. The PCR amplifications were carried out using the SensQuest Labcycler (Hannah Vogt Str, Germany), and the 16S rRNA and cagA gene $3^{\prime}$-end variable region products were separated on $1.5 \%$ and $2.5 \%$, respectively, agarose gels with ethidium bromide in tris acetate-EDTA (TAE) buffer. A molecular weight ladder of $100 \mathrm{bp}$ was used to determine the size of the bands.

2.2. Selection of Genomic DNA Samples for cagA Gene 3'-End Variable Region Sequencing. The DNA samples for commercial sequencing were selected based on the fragment sizes of the PCR amplified cagA gene $3^{\prime}$-end variable region that has been separated on $2.5 \%$ agarose gel. The representative samples for sequencing were a single band with molecular 
TABLE 1: Sets of primers for H. pylori detection and characterization.

\begin{tabular}{lcccc}
\hline Target gene & Primer name & Primer sequence $\left(5^{\prime}-3^{\prime}\right)$ & Tm $\left({ }^{\circ} \mathrm{C}\right)$ & Expected product size $(\mathrm{bp})$ \\
\hline \multirow{2}{*}{ H. pylori $16 S \mathrm{~S}$ RNA } & $\mathrm{F}^{\mathrm{a}}$ & TCCAACAACTAGCATCCATC & 52.2 & 127 \\
& $\mathrm{R}^{\mathrm{a}}$ & AGGAATACTCATTGCGAAGG & 52.2 & $207,285,387$, and 489 \\
Western type & $\mathrm{WF}$ & ATGATCTCGGCGGACGACCTTT & 60.7 & 57.3 \\
& $\mathrm{WR}$ & TGCGTGTGTGGCTGTTAGTAG & 557 \\
East Asia type & $\mathrm{EF}$ & GCATCAGCAGGTAAAGGAGTG & 58.8 & 5 \\
\hline
\end{tabular}

H. pylori $16 S$ rRNA primers (this study): $\mathrm{F}^{\mathrm{a}}$ : forward primer; $\mathrm{R}^{\mathrm{a}}$ : reverse primer. Western type: WF: forward primer; WR: reverse primer. EF: East Asia type forward primer [20].

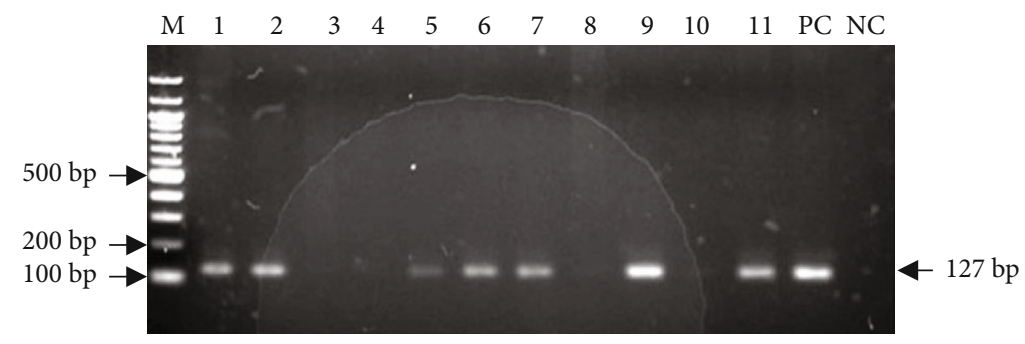

FIGURE 1: Detection of $\mathrm{H}$. pylori 16S RNA gene in Ghanaian isolates. A representative of ethidium bromide-stained $1.5 \%$ agarose gel electropherogram. Lane $\mathrm{M}=100$ bp molecular.

weight of either $207 \mathrm{bp}$ or $285 \mathrm{bp}$ and a double band with molecular weights of $207 \mathrm{bp}$ and $285 \mathrm{bp}$. Sample tubes containing the selected genomic DNA samples were clearly labelled and shipped for sequencing with instructions. The primer set that was used for the cagA $3^{\prime}$-end region amplification and sequencing is previously described [20].

2.3. Sequence Alignment. The translated CagA protein amino acid sequences in FASTA format were trimmed and aligned with similar sequences obtained from NCBI GenBank database using the European Molecular Biology LaboratoryEuropean Bioinformatics Institute (EMBL-EBI) platform.

\section{Results}

3.1. Identification of $H$. pylori by $16 S$ rRNA Amplification Using Conventional PCR. The $16 \mathrm{~S}$ rRNA gene of $H$. pylori was amplified in 50 (53.2\%) out of the 94 samples. H. pylori $16 \mathrm{~S}$ rRNA gene fragments and predicted size are shown in Figure 1.

3.2. Amplification and Percentage Distribution of $H$. pylori cagA Gene $3^{\prime}$-End Variable Region. All the 50 samples that were positive for $16 S \mathrm{rRNA}$ gene showed the presence of $\operatorname{cagA}$ gene $3^{\prime}$-end variable region. Based on the sizes of the amplified fragments (Figure 2), two different $H$. pylori variants were detected in the samples: a $207 \mathrm{bp}$ and $285 \mathrm{bp}$.

Percentage distribution of the cagA gene $3^{\prime}$-end variable sequences in the samples is shown in Figure 3. Bacteria variants that harboured variable $\operatorname{cag} A$ gene $3^{\prime}$-end variable sequence of band size $207 \mathrm{bp}$, indicating a single infection (70\%), were the most predominant compared to the mixed infection and the $285 \mathrm{bp}$ single infection type.
3.3. Alignment of Amino Acid Sequences of CagA Protein CTerminal with Reference Sequences. Alignment of amino acid sequences of cagA-positive $H$. pylori variants from the study samples with reference sequences from NCBI GenBank database is presented in Figure 4. The reference (USAATC C43503) sequence showed the conserved EPIYA-A and EPIYA-B and three variable EPIYA-C motifs (ABCCC type), while the WAfricaLSU strain EPIYA motifs were similar to the variants identified in this study. The sequences from the current study were obtained from a $207 \mathrm{bp}$ variant from the samples GH32 and GH62 with amino acids glycine, leucine, lysine, arginine, glycine, and glycine (GLKNGG) insertions and GH65 with a serine substitution (GLKNSG), at the Nterminal flanking sequence of EPIYA-A motif.

The 285 bp variant (GHA41) showed amino acids glycine, leucine, lysine, arginine, glycine lysine, aspartic acid, lysine, glycine, proline, and glutamic acid (GLKNGKDKGPE) insertions with a sequence pattern similar to the WAfricaLSU reference strain. The amino acid sequences of all the amplified fragments showed conserved EPIYA-A and EPIYA-B motifs as well as a single EPIYA-C motif which occurred at the first variable region of the CagA protein.

\section{Discussion}

H. pylori is regarded as one of the most commonly diverse microorganisms ever studied [21, 22]. Possible explanations for the strain diversity include the ability of the organism to excise short damaged nucleotide sequences using type III endonucleases and explore nucleotide excision repair pathways for bulky lesion repair and importation of exogenous DNA through the cytoplasmic membrane channel during DNA repairs [21, 22]. 


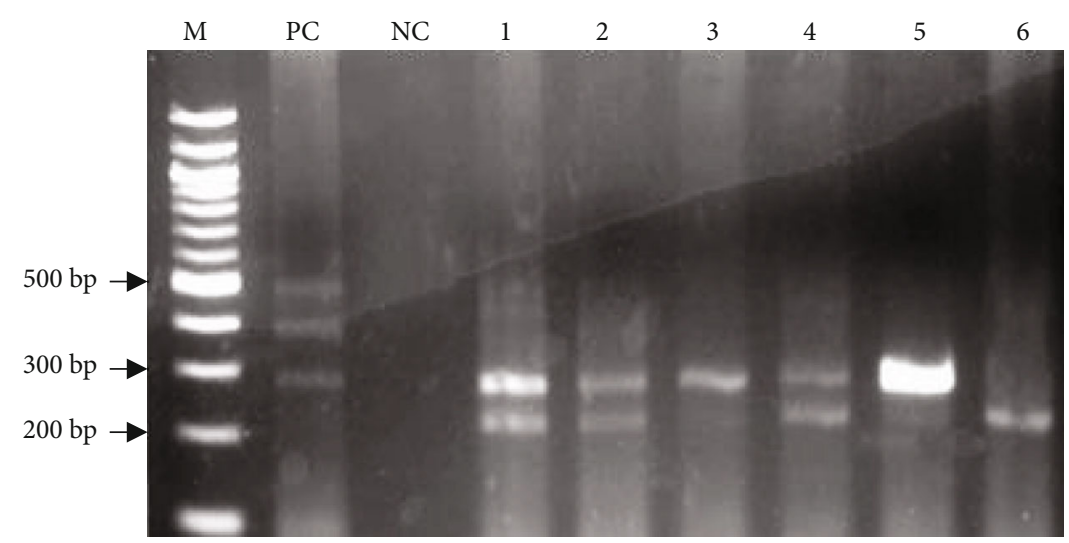

Figure 2: Detection of cagA gene $3^{\prime}$-end variable sequence in Ghanaian isolates. Representative ethidium bromide-stained $2.5 \%$ agarose gel electropherogram of multiplex PCR for the identification of the $H$. pylori cagA $3^{\prime}$ variable end sequence. Lane $\mathrm{M}=100 \mathrm{bp}$ molecular weight ladder; lanes 3 and 5: amplification of a single variable sequence of cagA gene of $H$. pylori strain with band size of $285 \mathrm{bp}$, and lane $6=207 \mathrm{bp}$. Lanes 1, 2, and 4: amplification of double variable sequences of cagA gene with band sizes $207 \mathrm{bp}$ and 285 bp; lane PC: positive control DNA of H. pylori strain (ATCC 43504) showing three cagA gene $3^{\prime}$-end variable sequences (ABCCC); NC: negative control.

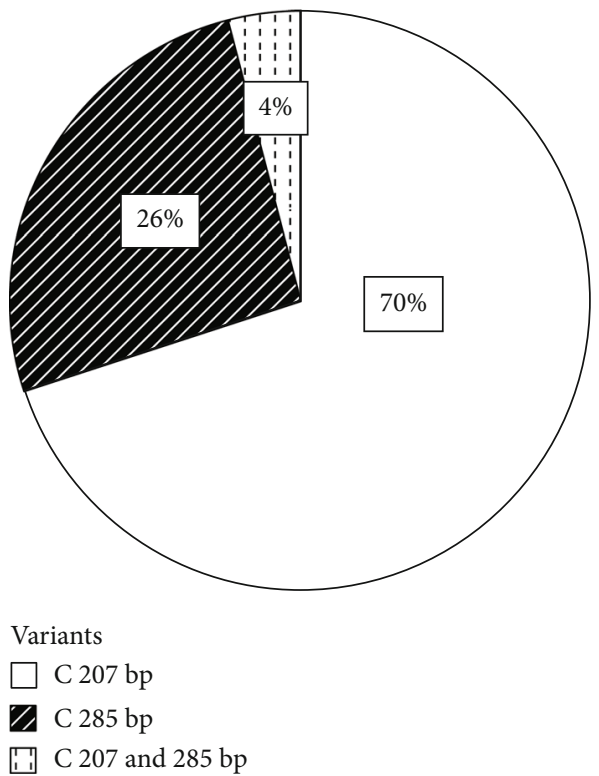

Figure 3: Percentage distribution of $H$. pylori cagA gene $3^{\prime}$-end variable region in the study samples.

Identification of the virulence factors and gene differences of $H$. pylori in a population is crucial since bacterial pathogenicity and diseases disparity largely depend on these factors [23]. The virulence factors, together with diet and host-pathogen response mechanism, play important roles in gastric disease outcome. The CagA protein is the most studied virulence factor encoded by a $40 \mathrm{~kb}$ cag-pathogenic island (cag-PAI), and the island is responsible for several bacterial virulence factors including type IV secreting system (T4SS) required for translocation of the CagA protein into the host cell [24]. cagA-positive H. pylori strain is associated with gastric disease compared to cagA-negative strain, and disease aggressiveness in patients is linked to genetic variability of the CagA protein [12].
The current study presents, for the first time, information on the CagA C-terminal variable region of $H$. pylori variants obtained from archival genomic DNA that was previously extracted from stomach biopsies of Ghanaian patients with gastric disease. This study showed a lower prevalence of cagA-positive strain compared to a previous study from the same population which showed a prevalence of $74.8 \%$ [19]. The relatively low detection of bacterial DNA reported in the current study may be due to the over 24month storage of the genomic DNA that was used. An inverse relationship between amount of DNA and storage time has been reported in a study in which microbial DNA depreciated at a rate of $6.6 \%$ per 10 days when samples were stored at $-20^{\circ} \mathrm{C}$ [25].

Our study showed two pathogenic H. pylori variants. The difference in the two variants was the different fragment size of the cagA $3^{\prime}$-end variable region; the smaller fragment variant was more predominant and showed a high prevalence of single infection. The two variants however share similar sequences at the CagA C-terminal variable and had EPIYAA, EPIYA-B, and EPIYA-C motifs with amino acid insertion at the N-terminal sequence flanking the EPIYA-A motif. Even though other studies have shown similar variations in the size of the $\operatorname{cag} A$ gene $3^{\prime \prime}$-end variable region $[10,20]$, the variants from this study had a complete deletion of EPIYA-CC and EPIYA-CCC and the flanking sequences.

This study reports $100 \%$ Western-type $H$. pylori variants ( $\mathrm{ABC}$ type) in the gastric biopsies that were used. A high prevalence of CagA ABC type monoinfection has been reported in patients diagnosed with gastric disease [26], and variants with more than one EPIYA-C motifs were associated with disease severity [27]. Patients diagnosed with gastric ulcer and cancer have been found to harbour $H$. pylori strains with EPIYA-ABCCC and ABCC motifs, respectively [10, 28], and the number of motifs correlated with inflamed cells [29]. On the contrary, a study observed that a single EPIYA-C motif phosphorylation was sufficient for cellular perturbation [30], and proinflammatory response to $H$. pylori infection 


USAATCC 4503
WAfricaLSU
GH 1
GH62
GH32
GH65
USAATCC43503
WAfricaLSU
GH41
GH62
GH32
GH65
USAATCC43503
WAfricaLSU
GH41
GH62
GH32
GH65
USAATCC43503
WAfricaLSU
GH41
GH62
GH32
GH65

EPIYA-A

EPIYA-B ----SDIKKELNEKFKNENNNNNNG------LENEPIYAKVNKKKTGQVASPEEPIYAQV AKNFSDIKKELNEKFKNFNNNNNGLKNGKDKGPEEPIYAQVNKKKTGQVASPEEPIYAQV AKNFSDIKKELNEKFKNFNNNNNGLKNGKDKGPEEPIYAQVNKKKTGQVASPEEPIYAQV AKNFSDIKKELNEKFKNFNNNNNGLKNGG-----EPIYAQVNKKKTGQVTSPEEPIYAQV AKNFSDIKKELNEKFKNFSNNNNGLKNGG-----EPIYAQVNKKKTGQVASPEEPIYAQV AKNFSDIKKELNEKFKNFNNNNNGLKNSG-----EPIYAQVNKKKTGQVASPEEPIYAQV EPIYA-C AKKVNAKIDRLNQA-ASGLGGVGQAGFPLKRHDKVDDLSKVGRSVSPEPIYAT I DDLGGP AKKVTQKIDQLNQA-ASGFGGVGQAGFPLKRHDKVDDLSKVGRSVSPEPIYATIDDLDGS AKKVTKKIDQLNQA-ASGFGGVGQAGFPLKRHDKVDDLSKVGRSVSPEPIYAT I DDLGGP AKKVTKKIDQLNQAATSGFGGVGQAGFPLKRHDKVDDLSKVGRSVSPEPIYAT I DDLGGS AKKVTKKIDQLNQA-ASGFGGVGQAGEPLKKHAKVEDLSKVGRSVSPEPIYATIDDLGGS AKKVTKKIDQLNQA-ASGFGGVGQAGFPLKKHAKVEDLSKVGRSVSPEPIYATIDDLGGS

EPIYA-C

EPIYA-C FPLKRHDKVDDLSKVGRSVSPEPIYATIDDLGGPFPLKRHDKVDDLSKVGRSVSPEPIYA FPLRKSAKVDD----------------------------------------------

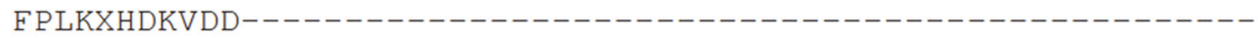

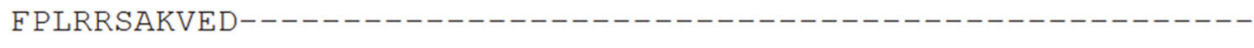
FPLRRSAAVDD-

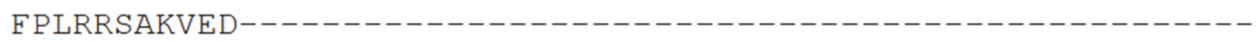
TIDDLGGPFPLKRHDKVDDLSKVGLSRNQELAQK I DNLSQAVSEAKA----------------------------LSKVGLSRNQELTQK I S LSQAVSEAKAGFFGNLEQT I DKL ----------------LSKVGRSREQEXTQKI DSLSQAVSEAKAGFFGNLEQT I DKL ----------------LSKVGRSREQEXTQKIDNLSQAVSEAKAGFFGNLEQT I DNL ---------------- LSKAGLSRNQELTQKI DSLSQAVSEAKAGFFSNLEQT I DNL 50 60 60 55 55 55

FIgUre 4: Variation of $H$. pylori CagA protein C-terminal in the Ghanaian patients. Alignment of amino acid sequences of the C-terminal in representative samples with reference sequences. The amino acid sequences and EPIYA motifs are presented in segments, and the numbers indicate the cumulative amino acid residues per sequence. GH: study variant from Ghana. Reference sequences are USA43504 (BAB20926.1) and WAfricaLSU (CVB36400.1). Reference sequences were retrieved from NCBI GenBank database.

was independent of the number of CagA EPIYA-C motifs that was phosphorylated [31].

The carcinogenic potential of CagA protein is determined by the dynamics of the tyrosine phosphorylation of EPIYA-C repeats [29, 32], and the intracellular phosphorylation exhibits preferential targeting of the EPIYA sites [13]. Phosphorylated EPIYA motifs result in the hummingbird phenotypic appearance of gastric cell lines, hall mark of cancers [33]. The mechanism of pathogenic $H$. pylori-induced cell morphological changes is through plasma membrane tethering of phosphorylated CagA and recruitment of $\mathrm{SH} 2$ domain-containing protein tyrosine phosphatase-2 (SHP2) from the cytoplasm to the plasma membrane $[14,30]$. The number of EPIYA motifs has been reported to potentiate SHP2 recruitment [15]. Plasma membrane tethering and phosphorylation of CagA are prerequisite for CagA-SHP2 interaction, and both processes require the EPIYA motifs [14]. The CagA-SHP2 interaction disrupts cell signalling leading to malignant transformation of mammalian cells via focal adhesion kinase (FAK) dephosphorylation [3436]. The molecular episode depolarizes gastric epithelial cells, disrupting gastric secretions and promoting chronic $H$. pylori colonization in the stomach [37].

The EPIYA phosphorylation differences were reported to account for the gastric pathophysiological actions of
H. pylori strains [38]. Even though the importance of the amino acid substitution or sequence insertion in the study variants is not known, specific amino acid sequences within the CagA $3^{\prime}$-end variable region have been reported to play a role in CagA protein translocation [39]. The current detected EPIYA variants and amino acid sequence differences, together, may explain the increased infection in the developing countries but low prevalence of gastric cancer cases.

\section{Conclusion}

In conclusion, the Western strain (ABC type) of $H$.pylori was the most predominant strain in the study population, and the two $H$. pylori variants detected differed by the size of the amplified fragment. Both variants showed amino acid substitution or sequence insertion at the $\mathrm{N}$-terminal sequence flanking the EPIYA-A and deletion of the second and third EPIYA-C motifs together with the flanking amino acid sequences. A larger sample size is required to confirm the preliminary data in the Ghanaian populace and to investigate further the clinical importance of the insertions and the presence of the single EPIYA-C motif in the CagA C-terminal variable region in gastric disease outcome. 


\section{Data Availability}

All data generated or analysed during this study are included in this published article.

\section{Disclosure}

The findings were presented at WACCBIP Research Conference-2019.

\section{Conflicts of Interest}

The authors declare no conflict of interest for this paper.

\section{Acknowledgments}

We thank Messrs. Raymond Lovelace Adjei and Sylvester Languon, all of Virology Laboratory, WACCBIP for their support in running the assays. Emmanuel Ayitey Tagoe was supported by a WACCBIP-World Bank ACE Masters/PhD fellowship (ACE02-WACCBIP: Awandare) and a WACCBIP-Wellcome Trust DELTAS PhD/postdoctoral fellowship (107755/Z/15/Z: Awandare).

\section{References}

[1] J. K. Y. Hooi, W. Y. Lai, W. K. Ng et al., "Global prevalence of helicobacter pylori infection: systematic review and meta-analysis," Gastroenterology, vol. 153, no. 2, pp. 420-429, 2017.

[2] T. Archampong, R. H. Asmah, E. K. Wiredu, R. K. Gyasi, K. N. Nkrumah, and K. Rajakumar, "Epidemiology of helicobacter pylori infection in dyspeptic Ghanaian patients," The Pan African Medical Journal, vol. 20, pp. 1-9, 2015.

[3] J. Y. Park, D. Forman, L. A. Waskito, Y. Yamaoka, and J. E. Crabtree, "Epidemiology of Helicobacter pylori and CagApositive infections and global variations in gastric cancer," Toxins (Basel), vol. 10, no. 4, pp. 163-183, 2018.

[4] S. L. Palframan, T. Kwok, and K. Gabriel, "Vacuolating cytotoxin A (VacA), a key toxin for Helicobacter pylori pathogenesis," Frontiers in Cellular and Infection Microbiology, vol. 2, pp. 1-9, 2012.

[5] S. P. Mane, M. G. Dominguez-Bello, M. J. Blaser et al., "Hostinteractive genes in Amerindian Helicobacter pylori diverge from their old world homologs and mediate inflammatory responses," Journal of Bacteriology, vol. 192, no. 12, pp. 3078-3092, 2010.

[6] M. Hatakeyama, "Helicobacter pylori CagA-A bacterial intruder conspiring gastric carcinogenesis," International Journal of Cancer, vol. 119, no. 6, pp. 1217-1223, 2006.

[7] A. E. Frick-Cheng, T. M. Pyburn, B. J. Voss, M. D. WH, M. D. Ohi, and T. L. Cover, "Molecular and structural analysis of the Helicobacter pylori cag type IV secretion system core complex," MBio, vol. 7, no. 1, pp. 167-176, 2016.

[8] M. Stein, P. Ruggiero, R. Rappuoli, and F. Bagnoli, "Helicobacter pylori CagA: from pathogenic mechanisms to its use as an anti-cancer vaccine," Frontiers in Immunology, vol. 4, no. 328, pp. 1-17, 2013.

[9] F. Vaziri, S. N. Peerayeh, M. Alebouyeh et al., "Novel effects of Helicobacter pylori CagA on key genes of gastric cancer signal transduction: a comparative transfection study," Pathogens and Disease, vol. 73, no. 3, pp. 1-8, 2015.
[10] F. O. Beltrán-Anaya, T. M. T. M. Poblete, A. Román-Román et al., "The EPIYA-ABCC motif pattern in CagA of Helicobacter pylori is associated with peptic ulcer and gastric cancer in Mexican population," BMC Gastroenterology, vol. 14, no. 1, pp. 223-239, 2014.

[11] M. Hatakeyama and H. Higashi, "Helicobacter pylori CagA: a new paradigm for bacterial carcinogenesis," Cancer Science, vol. 96, no. 12, pp. 835-843, 2005.

[12] Q. Li, J. Liu, Y. Gong, and Y. Yuan, "Association of CagA EPIYA-D or EPIYA-C phosphorylation sites with peptic ulcer and gastric cancer risks," Medicine (Baltimore), vol. 96, no. 17, pp. e6620-e6630, 2017.

[13] H. Suzuki, E. Iwasaki, and T. Hibi, "Helicobacter pylori and gastric cancer," Gastric Cancer, vol. 12, no. 2, pp. 79-87, 2009.

[14] H. Higashi, K. Yokoyama, Y. Fujii et al., "EPIYA motif is a membrane-targeting signal of Helicobacter pylori virulence factor CagA in mammalian cells," The Journal of Biological Chemistry, vol. 280, no. 24, pp. 23130-23137, 2005.

[15] L. Nagase, T. Hayashi, T. Senda, and M. Hatakeyama, "Dramatic increase in SHP2 binding activity of Helicobacter pylori Western CagA by EPIYA-C duplication: its implications in gastric carcinogenesis," Scientific Reports, vol. 5, pp. 1-13, 2015.

[16] T. Hayashi, M. Senda, N. Suzuki et al., "Differential mechanisms for SHP2 binding and activation are exploited by geographically distinct Helicobacter pylori CagA oncoproteins," Cell Reports, vol. 20, no. 12, pp. 2876-2890, 2017.

[17] L. A. Sicinschi, P. Correa, R. M. Peek et al., "CagA C-terminal variations in Helicobacter pylori strains from Colombian patients with gastric precancerous lesions," Clinical Microbiology and Infection, vol. 16, no. 4, pp. 369-378, 2010.

[18] N. R. Hussein, M. Mohammadi, Y. Talebkhan et al., "Differences in virulence markers between Helicobacter pylori strains from Iraq and those from Iran : potential importance of regional differences in $\mathrm{H}$. pylori- associated disease," vol. 46, no. 5, pp. 1774-1779, 2008.

[19] T. N. Archampong, R. H. Asmah, E. K. Aidoo et al., "Helicobacter pylori cagA and vacA genes in dyspeptic Ghanaian patients," BMC Research Notes, vol. 10, no. 1, p. 231, 2017.

[20] B. An, G. Lee, K. Lim, B. S. Moon, and J. B. Kim, "Identification of the repeated number of $C$ and $D$ regions of tyrosine phosphorylation motifs in Helicobacter pylori cagA using multiplex PCR," Microbiology and Immunology, vol. 52, no. 10, pp. 479-483, 2008.

[21] G. W. Liechti and J. B. Goldberg, "Helicobacter pylori salvages purines from extracellular host cell DNA utilizing the outer membrane-associated nuclease NucT," Journal of Bacteriology, vol. 195, no. 19, pp. 4387-4398, 2013.

[22] M. S. Dorer, J. Fero, and N. R. Salama, "DNA damage triggers genetic exchange in Helicobacter pylori," PLoS Pathogens, vol. 6, no. 7, pp. e1001026-e1001036, 2010.

[23] A. M. F. Abu-Taleb, R. S. Abdelattef, A. A. Abdel-Hady et al., "Prevalence of Helicobacter pylori cagA and iceA genes and their association with gastrointestinal diseases," International Journal of Microbiology, vol. 2018, 7 pages, 2018.

[24] S. Backert, N. Tegtmeyer, and W. Fischer, "Composition, structure and function of the Helicobacter pylori cag pathogenicity island encoded type IV secretion system," Future Microbiology, vol. 10, no. 6, pp. 955-965, 2015.

[25] V. Romanazzi, D. Traversi, E. Lorenzi, and G. Gilli, "Effects of freezing storage on the DNA extraction and microbial 
evaluation from anaerobic digested sludges," BMC Research Notes, vol. 8, no. 1, pp. 1-8, 2015.

[26] A. Vilar e Silva, M. R. Junior, R. M. Vinagre et al., "Evaluation of the pattern of EPIYA motifs in the Helicobacter pylori cagA gene of patients with gastritis and gastric adenocarcinoma from the Brazilian Amazon Region," International Journal of Bacteriology, vol. 2014, 6 pages, 2014.

[27] M. el Khadir, S. Alaoui Boukhris, D. A. L. L. A. H. Benajah et al., "_Helicobacter pylori_CagA EPIYA-C motifs and gastric diseases in Moroccan patients," Infection, Genetics and Evolution, vol. 66, pp. 120-129, 2018.

[28] S. Honarmand-Jahromy, F. Siavoshi, R. Malekzadeh, T. N. Sattari, and S. Latifi-Navid, "Multiple repeats of Helicobacter pylori CagA EPIYA-C phosphorylation sites predict risk of gastric ulcer in Iran," Microbial Pathogenesis, vol. 89, pp. 87-92, 2015.

[29] M. Ferreira Júnior, S. A. Batista, P. V. Vidigal et al., "Infection with CagA-positive Helicobacter pylori strain containing three EPIYA C phosphorylation sites is associated with more severe gastric lesions in experimentally infected Mongolian gerbils (Meriones unguiculatus)," European Journal of Histochemistry, vol. 59, no. 2, pp. 137-146, 2015.

[30] D. Mueller, N. Tegtmeyer, S. Brandt et al., "c-Src and c-Abl kinases control hierarchic phosphorylation and function of the CagA effector protein in Western and East Asian Helicobacter pylori strains," The Journal of Clinical Investigation, vol. 122, no. 4, pp. 1553-1566, 2012.

[31] K. S. Papadakos, I. S. Sougleri, A. F. Mentis, E. Hatziloukas, and D. N. Sgouras, "Presence of terminal EPIYA phosphorylation motifs in Helicobacter pylori CagA contributes to IL-8 secretion, irrespective of the number of repeats," PLoS One, vol. 8, no. 2, pp. e56291-e56302, 2013.

[32] S. A. Batista, G. A. Rocha, A. M. Rocha et al., "Higher number of Helicobacter pylori CagA EPIYA C phosphorylation sites increases the risk of gastric cancer, but not duodenal ulcer," BMC Microbiology, vol. 11, no. 1, pp. 61-68, 2011.

[33] I. S. Sougleri, K. S. Papadakos, M. P. Zadik, and M. Mavrivavagianni, "Helicobacter pylori CagA protein induces factors involved in the epithelial to mesenchymal transition (EMT) in infected gastric epithelial cells in an EPIYA- phosphorylationdependent manner," The FEBS Journal, vol. 283, no. 2, pp. 206-220, 2016.

[34] J. Zhang, F. Zhang, and R. Niu, "Functions of Shp2 in cancer," Journal of Cellular and Molecular Medicine, vol. 19, no. 9, pp. 2075-2083, 2015.

[35] J. Li, Y. Kang, L. Wei et al., "Tyrosine phosphatase Shp2 mediates the estrogen biological action in breast cancer via interaction with the estrogen extranuclear receptor," PLoS One, vol. 9, no. 7, pp. e102847-e102860, 2014.

[36] K. Miura, Y. Wakayama, M. Tanino et al., "Involvement of EphA2-mediated tyrosine phosphorylation of Shp2 in Shp2regulated activation of extracellular signal-regulated kinase," Oncogene, vol. 32, no. 45, pp. 5292-5301, 2013.

[37] M. A. Osman, G. S. Bloom, and E. A. Tagoe, "Helicobacter pylori-induced alteration of epithelial cell signaling and polarity: a possible mechanism of gastric carcinoma etiology and disparity," Cytoskeleton, vol. 70, no. 7, pp. 349-359, 2013.

[38] D. R. Bridge and M. D. Scott, "Polymorphism in the Helicobacter pylori CagA and VacA toxins and disease," Gut Microbes, vol. 4, no. 2, pp. 101-117, 2014.

[39] A. Tohidpour, "CagA-mediated pathogenesis of Helicobacter pylori," Microbial Pathogenesis, vol. 93, pp. 44-55, 2016. 